\title{
CARDIOVASCULAR COMPLICATIONS OF ACROMEGALY
}

\author{
Ł. Mizera, M. Elbaum, J. Daroszewski, M. Bolanowski* \\ Medical University, Diabetes and Isotope Therapy, Dept. of Endocrinology, Wroclaw, Poland
}

\begin{abstract}
Acromegaly is associated with increased mortality and decreased life expectancy. Cardiovascular disease is the principal cause of premature mortality in patients with acromegaly, accounting for about $60 \%$ of deaths. GH and/or IGF-I exert direct cardiac effects: enhance cardiac contractility, stimulate cardiomyocyte growth, influence calcium influx in cardiomyocytes. Cardiac remodelling is influenced by hypertension and insulin resistance. Among cardiovascular risk factors arterial hypertension, reported in $35 \%$ of patients with acromegaly, ranks among most important negative prognostic factors for mortality. Hypertension plays significant role in the development of cardiac hypertrophy, especially in older acromegalic patients and diastolic blood pressure is best predictive factor for cardiac hypertrophy. Therefore, early and aggressive hypertension treatment is essential for prognosis in acromegaly. Other important risk factors are: valvular defects, arrhythmias, endothelial dysfunction, heart failure, lipid abnormalities and coronary artery disease. Numerous studies suggest that patients with acromegaly are under threat of arrhythmias, especially those with structural heart abnormalities. Congestive heart failure as end-stage acromegalic cardiomyopathy occurs usually in older patients, with long-term uncontrolled disease and other cardiovascular and metabolic complications. Relation between acromegaly and coronary artery disease is controversial as it seems to be connected rather with classical cardiovascular risk factors than $\mathrm{GH}$ and IGF-1 overexpresion.
\end{abstract}

Key words: acromegaly, complications.

\section{INTRODUCTION}

Acromegaly is a chronic systemic disease caused by the benign pituitary adenoma secreting growth hormone $(\mathrm{GH})$ in excess, which peripheral effect is mediated by insulin-like growth factor 1 (IGF-I) produced by the liver. The incidence of acromegaly is 3-5/million/year, prevalence $40-130$ / million, recent population studies suggest greater prevalence of acromegaly than previously thought
(1-3). Majority of patients harbour macroadenoma $(\geq 10 \mathrm{~mm}$ ) at the diagnosis, typical clinical features and presence of systemic complications (4). Transsphenoidal neurosurgery is the therapy of primary choice for most acromegaly patients, but its efficacy is limited to about $50 \%$ depending on adenoma size, its expansion and neurosurgeon's experience. In patients who remain not cured after surgery, medical therapies are applied. Among them, somatostatin analogs (SA) are the first choice adjuvant therapy, other are GH receptor antagonist (pegvisomant) or dopamine agonist (cabergoline) as monotherapy or given additionally to SA. Stereotactic radiotherapy (radiosurgery) remains an alternative option. Uncontrolled disease is associated with increased risk for cardiovascular, respiratory, metabolic and neoplastic complications and higher mortality rates than in the general population $(5,6)$.

Cardiovascular disease is a principal cause of premature mortality in acromegaly. Increased mortality is characterized by 1.5-2.5 times higher standardized mortality ratio, what means shorter life expectancy of approximately 10 years in not cured patients. Another important factor is a 5-10 years delay in the final diagnosis what influences the progression of the disease and development of complications. Among factors affecting mortality in acromegaly, $\mathrm{GH}$ concentration, hypertension and heart disease are main ones, before other like disease or symptoms duration, diabetes etc $(7,8)$.

Both GH and IGF-I exert direct cardiac effects: enhance cardiac contractility, stimulate cardiomyocyte growth, reduce systemic vascular resistance, influence calcium ions influx and raise peak calcium ion levels in cardiomyocytes. On the other hand, cardiac remodelling is influenced by hypertension and insulin resistance. The final effect of GH action is an increase of cardiac contractility and left ventricle mass, decrease of wall stress and vascular resistance leading to the increase of cardiac performance (9).

*Correspondence to: Marek Bolanowski, Medical University, Diabetes and Isotope Therapy, Dept. of Endocrinology, Pasteura 4, 50-367, Wroclaw, Poland, E-mail: marek.bolanowski@umed.wroc.pl 


\section{HYPERTENSION}

Hypertension is among the most common complications of acromegaly. In meta-analysis of 2562 patients from 11 series the reported mean prevalence was $35 \%$ (ranging from 18 to $60 \%$ ) (10). However, data is based mainly on office measurements and only in a few studies utilised 24-h blood pressure (BP) ambulatory recording, thus outcomes may be overestimated (11). Nonetheless, research definitely shows prevalence higher than in general population with nearly doubled hazard ratio (12). As in general population incidence of hypertension in acromegaly increases with age, but occurrence is earlier and affected subjects are nearly 10 years younger (12). Prevalence is independent of duration of the disease, but related to the extent of GH hypersecretion (10).

Being one of the most common, it is also among the most disadvantageous complication, while it has been shown to be the major independent determinant of mortality (8) and factor worsening cardiac hypertrophy and progression towards heart failure.

There are certain differences in characteristic comparing to primary hypertension. In a group of 92 hypertensive acromegalics diastolic blood pressure was significantly higher and systolic significantly lower compared to controls indicating predominantly diastolic involvement (12). Non-dipper profile is also more commonly observed with the incidence reaching nearly $50 \%$ (10) and family history of hypertension is less common (12).

These distinctive features imply different pathogenesis of hypertension secondary to acromegaly from that of primary hypertension. The biological mechanisms underlying hypertension development in this entity seem to be complex and still are not fully explicated. Both direct effects of GH and IGF-I oversecretion as well as mediated by systemic changes like insulin resistance or occurrence of sleep apnoea syndrome seem to play a vital role (10).

\section{Sodium and water retention}

Acromegaly has been long connected with increased plasma volume by water and sodium retention (13) what most probably plays a key role in hypertension development (10). The exchangeable sodium was shown to be increased in active acromegaly (14) often being greater than values found in Conn's syndrome (15), correlate with blood pressure and GH $\log$ levels and decrease after successful treatment (15).
The precise means by which GH causes antinatriuretic effect are not completely understood. It seems that it occurs mainly, if not solely, without involvement of the activation of the renin-angiotensin system. Numerous studies suggest suppression of atrial natriuretic peptide (16), yet data shows no statistically significant differences between active and controlled acromegaly (17).

Recent research favor a direct effect of GH on sodium and water reabsorption in the kidney tubule. Exact segment of nephron where GH/IGF-I axis regulates sodium reabsorption is still uncertain. Although some human metabolic studies suggested that $\mathrm{GH}$ affects directly epithelial sodium channel in distal tubule (16).

\section{Renin-angiotensin-aldosterone (RAA)}

Studies on influence of GH/IGF-1 administration on RAA axis based on animals, normal and growth hormone deficient populations are scarce and provided conflicting results showing stimulatory (18) as well as no significant effect (19). In the studies on acromegaly plasma renin activity has been repeatedly reported to be low (10). There is also data demonstrating blunted aldosterone response to endogenous and exogenous angiotensin II with concurrent increased vascular response (rise in blood pressure) to exogenous angiotensin II (20). All of these outcomes may be consequences of sodium retention and volume expansion and indeed are found in sodium loaded normal subjects. Nevertheless, there is some research showing that the level of plasma renin seems to be lower than expected for the degree of sodium retention and aldosterone levels are neither supressed nor related to plasma renin activity (21). Together with the fact that GH receptors on adrenal cells have been identified it raises a question about direct stimulatory effect of GH on adrenals, which due to lack of data remains unanswered.

\section{Hyperinsulinemia}

$\mathrm{GH}$ excess is responsible for development of insulin resistance, which further causes hyperinsulinemia. GH actions are mainly mediated by increased lipolysis and free fatty acids production causing general increase of resistance to insulin in liver and other tissues such as skeletal muscles and adipose tissue. Another pathomechanism is direct effect of GH on increase in endogenous glucose production in liver and decrease of peripheral glucose metabolism in muscles (22-24). On the other hand, its 
indirect action via IGF-I may, in turn, facilitate weak insulin effects (25).

Insulin resistance and high circulating insulin levels, may increase blood pressure and induce development of hypertension in acromegaly by several mechanisms including stimulating transcellular sodium transport causing renal sodium reabsorption, increasing sympathetic activity and RAA axis, promoting vascular smooth cell growth, impairment of endothelial function and thus vasodilatation (10). In accordance with these facts blood pressure has been found higher in hyperinsulinemic patients with acromegaly (26).

\section{Sleep apnea syndrome}

Sleep apnea syndrome is a complex disease that affects various organs and systems and is observed in $20-80 \%$ of patients with acromegaly $(27,28)$. High prevalence is an effect of direct actions of GH and IGF-I on craniofacial bones and soft tissues. The wide range of anatomical changes includes: swelling of the tongue, changes in the mucous and cartilages, increased lung volume, geometry of rib cage and reduced elasticity of lungs $(27,29)$. This condition is generally known to predispose to hypertension and arrhythmias (30). Increase in BP is caused by multiple mechanisms including peripheral vasoconstriction induced by increased sympathetic activity provoked by periods of desaturation and re-oxygenation (3133). Intermittent hypoxemia has been shown to activate RAA system $(33,34)$. There is also vascular dysfunction and stimulation of systemic inflammation induced by an increase in oxidative stress, reduced production of endothelium-dependent vasodilator, such as nitric oxide (35-37).

\section{Arterial wall hypertrophy and endothelial dysfunction}

Hypertension is closely related to vascular alterations which include decreased arterial elasticity, endothelial dysfunction, media-to-lumen ratio of small resistance arteries and capillary rarefaction (3840). Remodelling of resistant vessels plays important role in pathophysiology of hypertension (41).

Various studies have shown that patients with acromegaly develop vascular dysfunctions such as increased arterial stiffness identified by arterial pulse wave velocity (aPWV) and reduction in blood flow-mediated dilatation which indicates an increased peripheral resistance and an impaired endothelial function $(10,42,43)$.
Paisley et al. identified an increased aPWV in patients with acromegaly compared with that in control subjects, but no difference in aPWV between patients with active or controlled disease. Further analysis revealed correlation between arterial pulse wave velocity and age, systolic BP, acromegaly and BMI. What is important, artery stiffness is greater in acromegaly than can be accounted for by the higher systolic BP or by age (44).

Rizzoni et al. performed micrographic analysis of small arteries collected from subcutaneous fat of a comprising 12 normotensive, 12 hypertensive and 9 subjects with acromegaly. The study revealed structural abnormalities in acromegalics such as increased media-to-lumen ratio, media thickness and wall thickness, and that these changes can be characterised by an inward hypertrophic remodelling, rather than an eutrophic remodelling, which is more common in patients with hypertension. They also found weak correlation between media-to-lumen ratio and level of circulating IGF-I (42).

\section{Effect of treatment on hypertension}

Analysis of 5 years of long-acting somatostatin analogs therapy performed by Colao et al. has shown significant improvement in prevalence of hypertension from around 46.7 to $22.2 \%$ (45). In retrospective cohort study by Sardella et al. 58 patients were treated for 24 months with either lanreotide autogel, octreotide LAR or pegvisomant in addition to SA or as standalone therapy. The previously hypertensive acromegalics obtained significant improvement in blood pressure control in both controlled and uncontrolled disease subgroups. While hypertension developed in up to $46 \%$ of normotensive acromegalics who were unable to achieve IGF-I normalization (46).

Successful transsphenoidal surgery caused significant decrease of 24-h systolic BP (47). On the other hand, Annamalai et al. revealed that during 24 weeks long presurgical treatment with lanreotide autogel therapy, although there was no change in systolic and diastolic blood pressure, both aortic pulse wave velocity and flow-mediated dilatation improved (43).

Considering mentioned data successful treatment may have beneficial effect on hypertension in acromegaly, but substantial number of patients remain hypertensive despite well-controlled disease and need additional management. The guidelines recommend standard treatment with antihypertensive drugs $(4,48)$. Due to an increased sodium reabsorption 
in kidneys through the epithelial sodium channel, usage of amiloride may be a viable therapeutic option (16). Treatment of sleep apnea syndrome should be started as early as possible duo to significant risk of exacerbating hypertension $(4,49)$.

\section{ATHEROSCLEROSIS AND CORONARY ARTERY DISEASE}

The relationship between acromegaly and coronary artery disease (CAD) according to currently obtainable data is controversial. Studies on this topic has provided conflicting results. Two studies, by Colao et al. (50) and Brevetti et al. (51), provided evidence of increased intima media in active acromegaly. However there was no increased prevalence of welldefined carotid plaques in the first and a limitation of not well matched control group in terms of equal distribution of cardiovascular risk factors in the latter $(52)$. Other studies $(53,54)$ negate these findings, one of them suggesting even lower IMT than in matched for cardiovascular risk factors, non-acromegalic group (53). Concluding, it seems the effect of acromegaly on IMT is secondary to cardiovascular risk factors, if any.

Aortic stiffness has been reported significantly higher, whereas aortic strain and distensibility significantly decreased in patients with active disease as compared to controls (55). These properties are positively and independently associated with atherosclerosis and predict occult CAD in general population (56).

Multiple studies suggest increased fibrinogen and MPV suggesting hypercoagulable state which is favourable to cardiovascular events (57-61).

Cannavo et al. assessed risk of atherosclerosis on the grounds of Agatson Score (AS) based on coronary calcifications found by multidetector computed tomography, which is considered hallmark of atherosclerosis, and Framingham Score (FS) calculation in 39 acromegalics. Authors concluded that $41 \%$ of studied subjects were at risk of atherosclerosis having increased AS or at least intermediate FS risk. Worth noting is that extent of coronary calcifications was correlated with FG and increased in patients with hypertension and diabetes mellitus but both studied parameters were not influenced significantly by control of acromegaly (62).

Conversely, Akutsu et al. (63) concluded that risk of CAD in acromegaly at the time of diagnosis is low and remains stable upon successful treatment.
Moreover, results from this study suggest that acromegalic patients at the time of diagnosis are even less affected by CAD than expected from the CAD risk profile in the general population. In accordance with this observation in one autopsy study, it was noted that only $11 \%$ of cases had CAD, which was less than expected from the patients' age (64). This data, until now scarce, would suggest not only lack of pro- but even antiatherogenic effect of GH/IGF1 excess and that the prevalence of coronary artery disease is connected with regular risk factors rather than with acromegaly per se.

On top of that the analysis of records collected from 57 endocrine centers by Schöfl et al., shows that prevalence of the myocardial infarction and stroke in patients with acromegaly treated in specialised centres was not increased compared to general population. Incidence of hypertension was higher in patients with cardiovascular event than those without, but the percentage of uncontrolled disease did not differ statistically between groups, further suggesting impact of classical risk factors but not GH/IGF-1 oversecretion (65).

Because there is no coherent evidence that acromegaly per se yields an additional risk on top of that resulting from known CAD risk factors, the conventional risk evaluation and prevention strategies have been proposed regarding the same guidelines as in general population (63).

\section{ACROMEGALIC CARDIOMYOPATHY}

Cardiomyopathy has been known to be connected with acromegaly since 1895 shortly after its first description (64). It is main and distinctive characteristics is cardiac hypertrophy, other are fibrosis, diastolic dysfunction impaired systolic function on exertion with decreased exercise tolerance and very rarely resting systolic dysfunction. The latter is restricted to the late stage of long-lasting active acromegaly.

\section{Cardiac hypertrophy and its determinants}

Overgrowth of the myocardium is biventricular and concentric (25). Its prevalence increases with age but occurs commonly even in young patients with relatively short, uncomplicated disease (66). Minniti et al. in a study of 20 acromegalic patients aged under 30 years, with normal blood pressure and glucose tolerance found evidence of cardiac hypertrophy in $20 \%$ of subjects (67). In long lasting acromegaly 
prevalence of cardiomegaly may reach even $70 \%$ normotensive and $90 \%$ hypertensive patients (64).

Occurrence of cardiac hypertrophy in patients without hypertension and metabolic disorders suggests specific cardiomyopathy caused by direct effect of GH excess on heart. Both mentioned factors, however, worsen the evolution of structural or functional changes. What is more, cardiac alterations seem to be more correlated with hypertension and glucose tolerance abnormalities than GH/IGF-1 oversecretion (68). As showed by Colao et al. in the study of 130 subjects with acromegaly, hypertension in these patients is strongly related to prevalence and severity of cardiac hypertrophy, diastolic function and ejection fraction impairment. Diabetes and impaired glucose tolerance, on the other hand, are connected with higher prevalence of cardiac performance disturbances but not hypertrophy (68). This highlights the major role of comorbidities management in acromegaly. Indeed, in more recent studies the prevalence of cardiomyopathy is lower than earlier reported, consistent with improving quality of concomitant conditions treatment (69). Other predictors of increased left ventricle (LV) mass and detrimental functional changes are $\mathrm{GH}$ and IGF-I levels, age (68) and disease duration (64).

\section{Cardiomyopathy evolution}

In the early stage neither cardiac performance is affected nor does dilation of the ventricles occur. In fact, initially cardiac output increases which, together with increased heart rate and lower peripheral vascular resistance, contributes to hyperkinetic syndrome (66). Within a few years of active disease duration, subclinical diastolic dysfunction occurs due to impaired relaxation. This can lead to compromised systolic function during physical exercise when ventricular filling is essential in sustaining increased heart performance as a pump, which in turn can be manifested as decreased physical effort tolerance. In the study by Fazio et al. using radionuclide angiography, authors found diastolic filling times at rest reduced by $19 \%$ in acromegalic patients and $73 \%$ of them were not able to increase ejection fraction by $5 \%$ on excretion fitting criteria of impaired cardiac performance. Interestingly, diastolic dysfunction occurs in acromegaly even when other complications like hypertension, coronary artery disease or glucose metabolism abnormalities are absent (70).

Finally, full-blown cardiomyopathy develops manifesting as dilation of the ventricles and resting systolic dysfunction with clinical signs of heart failure with reduced ejection fraction. However, it occurs rarely in approximately $3 \%$ of patients and is largely limited to subjects with long-lasting untreated acromegaly (71). Once developed, it severely worsens prognosis: Bihan et al. reported that 1- and 5-year mortality rates for patients with heart failure were 25 and $37.5 \%$, respectively (71).

\section{Pathophysiology}

It is not easy to explain the deleterious structural changes in heart occurring in long-lasting acromegaly as a direct consequence of GH/IGF-I per se (72). Short term GH or IGF-I excess seems to have rather beneficial than detrimental effects on heart. Via receptors for both molecules in heart it stimulates synthesis of contractile proteins, balanced growth of cardiomyocytes and interstitial elements (resulting in lack of fibrosis) and provides a model of physiological cardiac growth with unaltered capillary density and beneficial effect on myocyte short/long axis ratio (72). It also exerts positive influence on calcium ions influx and peak calcium ion levels in cardiomyocytes resulting in increased contractility and functional advantage (73). In some studies GH administered exogenously exerted favourable effects in patients with dilated cardiomyopathy. It was also shown in animal studies to prevent post infarction ventricular necrosis, apoptosis and remodelling. Complementing observations are that GH deficiency is linked with worse systolic function which improves after institution of replacement therapy and that subjects with lower IGF-I levels in the immediate postinfarction period had better cardiac performance and overall outcomes (72).

Yet it seems, that at some currently undetermined point of time changes in heart induced by $\mathrm{GH}$ excess become maladaptive and eventually lead to cardiac failure in acromegaly.

As showed by the autoptic study of 27 acromegalic patients conducted by Lie et al. histological findings in acromegalic heart are signs of myocarditis with lymphomononuclear cell infiltrates, necrosis, extensive replacement fibrosis and derangement of organ architecture (64). Frustaci et al. (74) reported 8 -fold increase in fibrosis in endomyocardial biopsies from acromegalic patients in advanced stage of the disease comparing to controls, which consisted of matched for age and sex patients after mitral valve replacement. What is more, authors found 495-fold and 305-fold increase in apoptosis of myocytes and nonmyocyte elements, respectively. This form of cell 
death can significantly impact myocardial mechanics by reducing the force-generating capacity of the muscle as well as the ability of developing resting tension with changes in sarcomere length. It also plays crucial role in development of non-acromegalic cardiomyopathy $(75,76)$. Indeed in the mentioned study the magnitude of myocyte apoptosis correlated with the extent of ejection fraction impairment. Degree of apoptosis as well as fibrosis was positively correlated with the duration of the disease.

On the contrary, in two more recent studies using MRI found low prevalence of fibrosis in studied population. In one study authors reported fibrosis in $3.5 \%$ (69) and in the another $14 \%$ of studied subjects in comparison to up to $85 \%$ in earlier autoptic studies (64). Authors pointed out that fibrosis may not have a relevant role in cardiac function in acromegaly, at least in these studied populations. The discordances may result from the worse control of comorbidities in the studied populations in the past that could have an important role in development of fibrosis (54).

\section{Effect of treatment}

Effective treatment can not only arrest the unfavourable structural and functional changes but also reverse them. Surgical cure as well as the use of medication (SA, pegvisomant) are both successful in this concern.

In a meta-analysis of 18 studies involving 290 patients treatment with SA has been shown to reverse cardiac hypertrophy, improve diastolic function, exercise tolerance and normalise impaired cardiac performance on exertion. A trend towards increase in systolic function has been observed (77). Excellent clinical response to octreotide in patient with acromegaly and dilated cardiomyopathy with reduced ejection fraction and recurrent pulmonary oedema who was a possible candidate for heart transplant has been reported (78).

The outcomes of pegvisomant and successful surgery are similar. Reduction in left ventricular hypertrophy indices and improvement in diastolic and systolic function parameters have been demonstrated for both treatment modalities $(47,79)$.

Fact that the treatment targeting GH levels reverses cardiac abnormalities further supports existence of specific acromegalic cardiomyopathy.

Interestingly, receptors for somatostatin, including ss2 and ss5 - which are target receptors for octreotide and lanreotide, are expressed on cardiac myocyte and interstitial cells (80). This raises a question about involvement of direct effect on heart of these drugs on their positive outcomes in acromegaly. In support of this theory De Mainis et al. show significant reduction of left ventricular mass in patients receiving SA treatment regardless of biochemical control.

Considering cardiomyopathy, the GH-lowering treatment is most beneficial when implemented early in the disease course, in young patients. For example Colao et al. observed normalisation of left ventricular hypertrophy and rise in LVEF on peak exercise in $100 \%$ and $80 \%$, respectively in patients aged $<40$ years and in less than $50 \%$ in patients aged $>40$ years $(81)$.

\section{ARRHYTHMIAS}

Cardiac rhythm have been less studied in acromegaly patients than the structural heart changes. LV hypertrophy and fibrosis, both reported as common findings in acromegaly, are associated with a higher incidence of arrhythmias and sudden death in many conditions other than acromegaly like hypertension or ischaemic heart disease. Fibrosis and connected with LV hypertrophy myofibrillar dearangement with anatomical uncoupling of cardiomyocytes may lead to slowed and non-homogenous conduction of action potential further leading to arrhythmias. Meta-analysis of studies including over 27,000 subjects (not suffering from acromegaly) found the odds ratio for supraventricular and ventricular arrhythmias to be 3.4 and 2.8 respectively in patients with left ventricular hypertrophy (82). Numerous studies show correlation between the amount of collagen in cardiac tissue and incidence of arrhythmias (83).

In studies by Herrmann et al. and Maffei et al. high prevalence of late potentials were observed. Late potentials (LPs) consist of low amplitude and high frequency signals in the terminal part of the QRS complex recorded in a signal-averaged electrocardiogram. Their occurrence is considered a predictor of serious ventricular tachyarrhythmias and can be associated with an increased risk of sudden cardiac death during the subsequent year (84). Both studies reported incidence of LPs in $23 \%$ patients with acromegaly which was significantly higher than in healthy control groups. In study by Herrmann et al. the prevalence was particularly high in patients with active acromegaly and reached $56 \%$ compared to $6 \%$ in cured/well-controlled group. The association with the active disease was independent of age, gender, duration of the disease and body mass index. On the contrary, Maffei found significant correlation with the duration but not activity of the disease. The 
correlation with disease duration would be expected considering that fibrosis is more frequent in long-lasting disease. Importantly authors observed correspondence of LP-positivity with premature ventricular complexes detected in 24-hour Holter monitoring for the first time demonstrating arrhythmogenic potential of LPs in acromegaly however more studies are required to drive a substantial conclusions in this matter.

In a study by Kahaly et al. (85) authors found complex ventricular but not supraventricular arrhythmias to be significantly more prevalent and severe in patients than in controls in 24-h ECG Holter monitoring. Abnormalities were detectable in $48 \%$ of patients compared to $12 \%$ in controls. Frequency correlated with disease duration while severity with cardiac hypertrophy.

Rodrigues et al. (86) reported ventricular arrhythmias in $41 \%$ studied patients with acromegaly, however among the 14 reported 12 were asymptomatic ventricular extrasystoles which are commonly found in healthy subjects and most often considered not clinically important, the other two were asymptomatic ventricular bigeminism and ventricular tachycardia in a patient with ischaemic heart disease.

Conversely, Warszawski et al. found no clinically relevant arrhythmias in 24-h ECG Holter monitoring neither in treatment naive acromegalics nor in patients after 1 year of SA treatment. Possible explanation of this finding could be the fact that in the study population only two patients presented left ventricular hypertrophy and only three had fibrosis detected by MRI, indicating at the same time that rhythm disturbances in acromegaly are limited to patients with structural abnormalities.

Particular rhythm abnormality known LV dyssynchrony can be associated with acromegaly. It is defined as the loss of the simultaneous peak contraction of corresponding cardiac segments. Kırış et al. in the study performed on group of 60 patients, 30 of whom had active acromegaly reported higher prevalence of LV hypertrophy in acromegalics compared to control group and it significant correlation with LV dyssynchrony. Authors also reported notable correlation between GH and IGF-I levels and interstitial fibrosis (87).

Concluding, there is some data providing evidence that patients with acromegaly are at high risk of arrhythmias, especially those with structural cardiac abnormalities, however, for this relationship to be well-established it still needs to be studied more extensively.

\section{HEART VALVE DISEASE}

Pathophysiological background of valve disease in acromegaly is based on the unmediated effect of GH and IGF-Ion connective tissue manifesting as dysregulation in metalloproteinases expression, proteoglycan synthesis as well as collagen and mucopolysacharides deposition.

Valve abnormalities may be further aggravated by acromegaly aortic root dilatation which had been connected with acromegaly and documented in about $26 \%$ of a 42 patients in one study (88). This condition was in turn positively correlated with left ventricular mass.

The findings of heart valve disease in acromegaly consist of aortic and mitral regurgitation. Lie et al. (64) found mitral and aortic abnormalities in $19 \%$ of their autopsy series.

Pereira et al. (89) in the echocardiographic study of 40 patients with acromegaly found aortic regurgitation in $30 \%$ and mitral regurgitation in $5 \%$ of patients. These values were statistically significantly higher than in matched controls in which they totalled 7 and $0 \%$, respectively. Furthermore, authors pointed out that frequency of valvular abnormalities correlates with duration of disease and calculated that there was $19 \%$ increase in odds ratio with every year of GH excess duration.

Even higher prevalence was reported by Colao et al. (90) who found $86 \%$ of 42 studied active and $74 \%$ cured patients with acromegaly affected by valve disease predominantly aortic regurgitation. Both values significantly differed from controls matched for each group in which prevalence was $24 \%$ and $9 \%$ respectively. Cardiac valve abnormalities were more frequent in individuals with left ventricular hypertrophy in both groups, however in acromegaly, but not in controls, valve dysfunction was also highly prevalent in subjects with normal ventricular mass occurring in $75 \%$ active and 54\% cured patients.

Van der Klaauw et al. (91) in observational study performed on 37 acromegalics investigated change in the prevalence of valve regurgitation with time in active and controlled disease in the mean follow up of about 2 years. Authors found a significant increase from baseline $56 \%$ to $88 \%$ in active and no change in controlled disease, further documenting cumulative effect of $\mathrm{GH}$ overexpression on deterioration of valve function. The results also pointed out the irreversible but stable character of this abnormality in inactive acromegaly. Additionally investigators found, conversely to study by Colao et al., no association of valve dysfunction with left ventricular hypertrophy, thus demonstrating 
that the effect of $\mathrm{GH}$ excess on connective tissue rather than changes in ventricular diameter is the cause of this complication in studied population.

In con, acromegaly is associated with high incidence of heart valve disease, predominantly aortic regurgitation, which increases with the disease duration. Successful treatment of acromegaly, understood as achieving hormonal normalisation, does not undo the valve damage, but reduces its further worsening.

Although recent data (92) suggest decreased role of traditional cardiovascular complications reflecting mortality of acromegalic patients, it still remains an important factor. Relative normalization of mortality rates together with biochemical control of the disease in the last decade is caused by greater efficacy of neurosurgery and adjuvant medical therapies. In addition increased life expectancy recently shift from circulatory to cancer related deaths during long term follow up has been observed (93). Nevertheless, cardiovascular mortality risk must be taken in consideration in the patients with acromegaly, especially those with uncontrolled disease due to delayed diagnosis or lesser availability of modern efficacious therapies.

\section{Conflict of interest}

The authors declare that they have no conflict of interest.

\section{References}

1. Daly AF, Rixhon M, Adam C, Dempegioti A, Tichomirowa MA, Beckers A. High Prevalence of Pituitary Adenomas: A CrossSectional Study in the Province of Liège, Belgium. The Journal of Clinical Endocrinology \& Metabolism 2006;91:4769-75. doi:10.1210/jc.2006-1668.

2. Fernandez A, Karavitaki N, Wass JAH. Prevalence of pituitary adenomas: a community-based, cross-sectional study in Banbury (Oxfordshire, UK). Clinical Endocrinology 2010;72:377-82. doi:10.1111/j.1365-2265.2009.03667.x.

3. Gheorghiu M. News in Acromegaly. Acta Endocrinologica (Bucharest) 2017;13:129-130. doi:10.4183/aeb.2017.129.

4. Melmed S, Casanueva FF, Klibanski A, Bronstein MD, Chanson P, Lamberts SW, Strasburger CJ, Wass JA, Giustina A. A consensus on the diagnosis and treatment of acromegaly complications. Pituitary 2013;16:294-302. doi:10.1007/s11102-012-0420-x.

5. Melmed S, Bronstein MD, Chanson P, Klibanski A, Casanueva FF, Wass JAH, Strasburger CJ, Luger A, Clemmons DR, Giustina A. A Consensus Statement on acromegaly therapeutic outcomes. Nat Rev Endocrinol 2018;14:552-561. doi:10.1038/s41574-018-0058-5. 6. Bolanowski M, Ruchała M, Zgliczyński W, Kos-Kudła B, Bałdys-Waligórska A, Zieliński G, Bednarczuk T, HubalewskaDydejczyk A, Kamiński G, Marek B, Daroszewski J, Waśko R, Lewiński A. Akromegalia - nowe spojrzenie na pacjenta. Polskie propozycje postępowania diagnostyczno-terapeutycznego w akromegalii w świetle aktualnych doniesień. Endokrynologia Polska 2014;65:326-331. doi:10.5603/EP.2014.0045.

7. Dekkers OM, Biermasz NR, Pereira AM, Romijn JA, Vandenbroucke JP. Mortality in acromegaly: a metaanalysis. J Clin
Endocrinol Metab 2008;93:61-67. doi:10.1210/jc.2007-1191. 8. Holdaway IM, Rajasoorya RC, Gamble GD. Factors influencing mortality in acromegaly. J Clin Endocrinol Metab 2004;89:667674. doi:10.1210/jc.2003-031199.

9. Isgaard J, Arcopinto M, Karason K, Cittadini A. GH and the cardiovascular system: an update on a topic at heart. Endocrine 2015;48:25-35. doi:10.1007/s12020-014-0327-6.

10. Bondanelli M, Ambrosio MR, degli Uberti EC. Pathogenesis and prevalence of hypertension in acromegaly. Pituitary 2001;4:239-249. 11. Costenaro F, Martin A, Horn RF, Czepielewski MA, Rodrigues TC. Role of ambulatory blood pressure monitoring in patients with acromegaly. J Hypertens 2016;34:1357-1363. doi:10.1097/ HJH.0000000000000962.

12. Vitale G, Pivonello R, Auriemma RS, Guerra E, Milone F, Savastano S, Lombardi G, Colao A. Hypertension in acromegaly and in the normal population: prevalence and determinants. Clin Endocrinol (Oxf) 2005;63:470-476. doi:10.1111/j.1365-2265.2005.02370.x.

13. Ikkos D, Luft R, Sjögren B. Body water and sodium in patients with acromegaly 1. J Clin Invest 1954;33:989-994.

14. Møller J, Nielsen S, Hansen TK. Growth hormone and fluid retention. Horm Res 1999;51 Suppl 3:116-120. doi:10.1159/000053173.

15. Davies DL, Beastall GH, Connell JM, Fraser R, McCruden D, Teasdale GM. Body composition, blood pressure and the reninangiotensin system in acromegaly before and after treatment. J Hypertens Suppl 1985;3:S413-415.

16. Kamenický P, Mazziotti G, Lombès M, Giustina A, Chanson P. Growth hormone, insulin-like growth factor-1, and the kidney: pathophysiological and clinical implications. Endocr Rev 2014;35:234-281. doi:10.1210/er.2013-1071.

17. Deray G, Chanson P, Maistre G, Warnet A, Eurin J, Barthelemy C, Masson F, Martinez F, Lubetzki J, Legrand JC. Atrial natriuretic factor in patients with acromegaly. Eur J Clin Pharmacol 1990;38:409-413.

18. Wyse B, Waters M, Sernia C. Stimulation of the renin-angiotensin system by growth hormone in Lewis dwarf rats. Am J Physiol 1993;265:E332-339. doi:10.1152/ajpendo.1993.265.2.E332.

19. Møller J, Jørgensen JO, Marqversen J, Frandsen E, Christiansen JS. Insulin-like growth factor I administration induces fluid and sodium retention in healthy adults: possible involvement of renin and atrial natriuretic factor. Clin Endocrinol (Oxf) 2000;52:181-186. 20. Moore TJ, Thein-Wai W, Dluhy RG, Dawson-Hughes BF, Hollenberg NK, Williams GH. Abnormal adrenal and vascular responses to angiotensin II and an angiotensin antagonist in acromegaly. J Clin Endocrinol Metab 1980;51:215-222. doi:10.1210/jcem-51-2-215.

21. Karlberg BE, Ottosson A-M. Acromegaly and hypertension: role of the renin-angiotensin-aldosterone system. Acta Endocrinol 1982;100:581-587. doi:10.1530/acta.0.1000581.

22. Clemmons DR. Roles of insulin-like growth factor-I and growth hormone in mediating insulin resistance in acromegaly. Pituitary 2002;5:181-183.

23. Møller N, Jørgensen JOL. Effects of growth hormone on glucose, lipid, and protein metabolism in human subjects. Endocr Rev 2009;30:152-177. doi:10.1210/er.2008-0027.

24. Møller N, Schmitz O, Jøorgensen JO, Astrup J, Bak JF, Christensen SE, Alberti KG, Weeke J. Basal- and insulin-stimulated substrate metabolism in patients with active acromegaly before and after adenomectomy. J Clin Endocrinol Metab 1992;74:1012-9. doi:10.1210/jcem.74.5.1569148.

25. Colao A, Ferone D, Marzullo P, Lombardi G. Systemic Complications of Acromegaly: Epidemiology, Pathogenesis, and Management. Endocrine Reviews 2004;25:102-52. doi:10.1210/ er.2002-0022.

26. Ikeda T, Terasawa H, Ishimura M, Ochi H, Ohtani I, Fujiyama $\mathrm{K}$, Hoshino T, Tanaka Y, Mashiba H. Correlation between blood pressure and plasma insulin in acromegaly. J Intern Med 1993;234:61-63. 
27. Dostalova S, Sonka K, Smahel Z, Weiss V, Marek J, Horinek D. Craniofacial abnormalities and their relevance for sleep apnoea syndrome aetiopathogenesis in acromegaly. Eur $\mathrm{J}$ Endocrinol 2001;144:491-497.

28. Weiss V, Sonka K, Pretl M, Dostálová S, Klozar J, Rambousek $\mathrm{P}$, Marek J, Haas T. Prevalence of the sleep apnea syndrome in acromegaly population. J Endocrinol Invest 2000;23:515-519. doi:10.1007/BF03343767.

29. Pivonello R, Auriemma RS, Grasso LF, Pivonello C, Simeoli C, Patalano R, Galdiero M, Colao A. Complications of acromegaly: cardiovascular, respiratory and metabolic comorbidities. Pituitary 2017;20:46-62. doi:10.1007/s11102-017-0797-7.

30. Ip MS, Tan KC, Peh WC, Lam KS. Effect of Sandostatin LAR on sleep apnoea in acromegaly: correlation with computerized tomographic cephalometry and hormonal activity. Clin Endocrinol (Oxf) 2001;55:477-483.

31. Narkiewicz K, van de Borne PJ, Pesek CA, Dyken ME, Montano N, Somers VK. Selective potentiation of peripheral chemoreflex sensitivity in obstructive sleep apnea. Circulation 1999;99:11831189.

32. Narkiewicz K, van de Borne PJ, Cooley RL, Dyken ME, Somers VK. Sympathetic activity in obese subjects with and without obstructive sleep apnea. Circulation 1998;98:772-776.

33. Shell B, Faulk K, Cunningham JT. Neural Control of Blood Pressure in Chronic Intermittent Hypoxia. Curr Hypertens Rep 2016;18:19. doi:10.1007/s11906-016-0627-8.

34. Nishijima T, Tajima K, Yamashiro Y, Hosokawa K, Suwabe A, Takahashi K, et al. Elevated Plasma Levels of Soluble (Pro)Renin Receptor in Patients with Obstructive Sleep Apnea Syndrome in Parallel with the Disease Severity. Tohoku J Exp Med 2016;238:32538. doi:10.1620/tjem.238.325.

35. Møller DS, Lind P, Strunge B, Pedersen EB. Abnormal vasoactive hormones and 24-hour blood pressure in obstructive sleep apnea. Am J Hypertens 2003;16:274-80.

36. Khayat RN, Varadharaj S, Porter K, Sow A, Jarjoura D, Gavrilin MA, et al. Angiotensin Receptor Expression and Vascular Endothelial Dysfunction in Obstructive Sleep Apnea. Am J Hypertens 2018;31:355-61. doi:10.1093/ajh/hpx174.

37. Gjørup PH, Sadauskiene L, Wessels J, Nyvad O, Strunge B, Pedersen EB. Abnormally increased endothelin-1 in plasma during the night in obstructive sleep apnea: relation to blood pressure and severity of disease. Am J Hypertens 2007;20:44-52. doi:10.1016/j. amjhyper.2006.05.021.

38. Tsioufis C, Dimitriadis K, Katsiki N, Tousoulis D. Microcirculation in Hypertension: An Update on Clinical Significance and Therapy. Curr Vasc Pharmacol 2015;13:413-417.

39. Pabuccu T, Baris N, Ozpelit E, Akdeniz B, Guneri S. The relationship between resistant hypertension and arterial stiffness. Clin Exp Hypertens 2012;34:57-62. doi:10.3109/10641963.2011.618203. 40. Coutinho T, Bailey KR, Turner ST, Kullo IJ. Arterial stiffness is associated with increase in blood pressure over time in treated hypertensives. J Am Soc Hypertens 2014;8:414-421. doi:10.1016/j. jash.2014.03.330.

41. Laurent S, Boutouyrie P. The structural factor of hypertension: large and small artery alterations. Circ Res 2015;116:1007-1021. doi:10.1161/CIRCRESAHA.116.303596.

42. Rizzoni D, Porteri E, Giustina A, De Ciuceis C, Sleiman I, Boari GE, Castellano M, Muiesan ML, Bonadonna S, Burattin A, Cerudelli B, Agabiti-Rosei E. Acromegalic patients show the presence of hypertrophic remodeling of subcutaneous small resistance arteries. Hypertension 2004;43:561-565. doi:10.1161/01. HYP.0000114604.52270.05.

43. Annamalai AK, Webb A, Kandasamy N, Elkhawad M, Moir S, Khan F, Maki-Petaja K, Gayton EL, Strey CH, O'Toole S, Ariyaratnam S, Halsall DJ, Chaudhry AN, Berman L, Scoffings DJ, Antoun NM, Dutka DP, Wilkinson IB, Shneerson JM, Pickard JD, Simpson HL, Gurnell M. A comprehensive study of clinical, biochemical, radiological, vascular, cardiac, and sleep parameters in an unselected cohort of patients with acromegaly undergoing presurgical somatostatin receptor ligand therapy. J Clin Endocrinol Metab 2013;98:1040-1050. doi:10.1210/jc.2012-3072.

44. Paisley AN, Banerjee M, Rezai M, Schofield RE, Balakrishnannair S, Herbert A, Lawrance JA, Trainer PJ, Cruickshank JK. Changes in arterial stiffness but not carotid intimal thickness in acromegaly. J Clin Endocrinol Metab 2011;96:1486-1492. doi:10.1210/jc.2010-2225. 45. Colao A, Auriemma RS, Galdiero M, Lombardi G, Pivonello R. Effects of initial therapy for five years with somatostatin analogs for acromegaly on growth hormone and insulin-like growth factor-I levels, tumor shrinkage, and cardiovascular disease: a prospective study. J Clin Endocrinol Metab 2009;94:3746-3756. doi:10.1210/ jc.2009-0941.

46. Sardella C, Urbani C, Lombardi M, Nuzzo A, Manetti L, Lupi I, Rossi G, Del Sarto S, Scattina I, Di Bello V, Martino E, Bogazzi F. The beneficial effect of acromegaly control on blood pressure values in normotensive patients. Clin Endocrinol (Oxf) 2014;81:573-581. doi:10.1111/cen.12455.

47. Minniti G, Moroni C, Jaffrain-Rea ML, Esposito V, Santoro A, Affricano C, Cantore G, Tamburrano G, Cassone R. Marked improvement in cardiovascular function after successful transsphenoidal surgery in acromegalic patients. Clin Endocrinol (Oxf) 2001;55:307-313.

48. Katznelson L, Laws ER Jr, Melmed S, Molitch ME, Murad MH, Utz A, Wass JA; Endocrine Society. Acromegaly: An Endocrine Society Clinical Practice Guideline. The Journal of Clinical Endocrinology \& Metabolism 2014;99:3933-3951. doi:10.1210/ jc. 2014-2700.

49. Gonzaga C, Bertolami A, Bertolami M, Amodeo C, Calhoun D. Obstructive sleep apnea, hypertension and cardiovascular diseases. Journal of Human Hypertension 2015;29:705-712. doi:10.1038/ jhh.2015.15.

50. Colao A, Spiezia S, Cerbone G, Pivonello R, Marzullo P, Ferone D, Di Somma C, Assanti AP, Lombardi G. Increased arterial intimamedia thickness by B-M mode echodoppler ultrasonography in acromegaly. Clin Endocrinol (Oxf) 2001;54:515-524.

51. Brevetti G, Marzullo P, Silvestro A, Pivonello R, Oliva G, di Somma C, Lombardi G, Colao A. Early vascular alterations in acromegaly. J Clin Endocrinol Metab 2002;87:3174-3179. doi: $10.1210 /$ jcem.87.7.8643.

52. Clayton RN. Cardiovascular function in acromegaly. Endocr Rev 2003;24:272-277. doi:10.1210/er.2003-0009.

53. Otsuki M, Kasayama S, Yamamoto H, Saito H, Sumitani S, Kouhara H, Saitoh Y, Ohnishi T, Arita N. Characterization of premature atherosclerosis of carotid arteries in acromegalic patients. Clin Endocrinol (Oxf) 2001;54:791-796.

54. Bogazzi F, Battolla L, Spinelli C, Rossi G, Gavioli S, Di Bello V, Cosci C, Sardella C, Volterrani D, Talini E, Pepe P, Falaschi F, Mariani G, Martino E. Risk factors for development of coronary heart disease in patients with acromegaly: a five-year prospective study. J Clin Endocrinol Metab 2007;92:4271-4277. doi:10.1210/jc.20071213.

55. Topaloglu O, Sayki Arslan M, Turak O, Ginis Z, Sahin M, Cebeci M, Ucan B, Cakir E, Karbek B, Ozbek M, Cakal E, Delibasi T. Three noninvasive methods in the evaluation of subclinical cardiovascular disease in patients with acromegaly: epicardial fat thickness, aortic stiffness and serum cell adhesion molecules. Clin Endocrinol (Oxf) 2014;80:726-734. doi:10.1111/cen.12356.

56. Gürel E, Tigen K, Karaahmet T, Gecmen C, Mutlu B, Bulut M, Basaran Y. Aortic elastic properties predict occult coronary artery disease: a multidetector row computed tomography study. Kardiol Pol 2015;73:101-108. doi:10.5603/KP.a2014.0188.

57. Demirpence M. Mean Platelet Volume and Platelet Function Analysis in Acromegalic Patients Before and after Treatment. Acta Endocrinologica (Bucharest) 2016;12:401-406. doi:10.4183/ aeb.2016.401.

58. Delaroudis SP, Efstathiadou ZA, Koukoulis GN, Kita MD, Farmakiotis D, Dara OG, Goulis DG, Makedou A, Makris P, Slavakis 


\section{Ł. Mizera et al.}

A, Avramides AI. Amelioration of cardiovascular risk factors with partial biochemical control of acromegaly. Clin Endocrinol (Oxf) 2008;69:279-84. doi:10.1111/j.1365-2265.2008.03181.x.

59. Landin-Wilhelmsen K, Tengborn L, Wilhelmsen L, Bengtsson BA. Elevated fibrinogen levels decrease following treatment of acromegaly. Clin Endocrinol (Oxf) 1997;46:69-74.

60. Colak A, Yilmaz H, Temel Y, Demirpence M, Simsek N, Karademirci İ, Bozkurt U, Yasar E. Coagulation parameters and platelet function analysis in patients with acromegaly. J Endocrinol Invest 2016;39:97-101. doi:10.1007/s40618-015-0300-0.

61. Kałuzny M, Bolanowski M, Daroszewski J, Szuba A. The role of fibrinogen and CRP in cardiovascular risk in patients with acromegaly. Endokrynol Pol 2010;61:83-88.

62. Cannavo S, Almoto B, Cavalli G, Squadrito S, Romanello G, Vigo MT, Fiumara F, Benvenga S, Trimarchi F. Acromegaly and coronary disease: an integrated evaluation of conventional coronary risk factors and coronary calcifications detected by computed tomography. J Clin Endocrinol Metab 2006;91:3766-3772. doi:10.1210/jc.2005-2857.

63. Akutsu H, Kreutzer J, Wasmeier G, Ropers D, Rost C, Möhlig M, Wallaschofski H, Buchfelder M, Schöfl C. Acromegaly per se does not increase the risk for coronary artery disease. Eur J Endocrinol 2010;162:879-886. doi:10.1530/EJE-09-0945.

64. Lie JT. Pathology of the heart in acromegaly: anatomic findings in 27 autopsied patients. Am Heart J 1980;100:41-52.

65. Schöfl C, Petroff D, Tönjes A, Grussendorf M, Droste M, Stalla G, Jaursch-Hancke C, Störmann S, Schopohl J. Incidence of myocardial infarction and stroke in acromegaly patients: results from the German Acromegaly Registry. Pituitary 2017;20:635-642. doi:10.1007/ s11102-017-0827-5.

66. Fazio S, Cittadini A, Biondi B, Palmieri EA, Riccio G, Bonè F, Oliviero U, Saccà L. Cardiovascular effects of short-term growth hormone hypersecretion. J Clin Endocrinol Metab 2000;85:179-182. doi:10.1210/jcem.85.1.6313.

67. Minniti G, Jaffrain-Rea ML, Moroni C, Baldelli R, Ferretti E, Cassone R, Gulino A, Tamburrano G. Echocardiographic evidence for a direct effect of GH/IGF-I hypersecretion on cardiac mass and function in young acromegalics. Clin Endocrinol (Oxf) 1998;49:101-106. 68. Colao A, Baldelli R, Marzullo P, Ferretti E, Ferone D, Gargiulo P, Petretta M, Tamburrano G, Lombardi G, Liuzzi A. Systemic hypertension and impaired glucose tolerance are independently correlated to the severity of the acromegalic cardiomyopathy. J Clin Endocrinol Metab 2000;85:193-199. doi:10.1210/jcem.85.1.6318. 69. dos Santos Silva CM, Gottlieb I, Volschan I, Kasuki L, Warszawski L, Balarini Lima GA, Xavier SS, Pedrosa RC, Neto LV, Gadelha MR. Low Frequency of Cardiomyopathy Using Cardiac Magnetic Resonance Imaging in an Acromegaly Contemporary Cohort. J Clin Endocrinol Metab 2015;100:4447-4455. doi:10.1210/jc.2015-2675. 70. Fazio S, Cittadini A, Cuocolo A, Merola B, Sabatini D, Colao A, Biondi B, Lombardi G, Saccà L. Impaired cardiac performance is a distinct feature of uncomplicated acromegaly. J Clin Endocrinol Metab 1994;79:441-446. doi:10.1210/jcem.79.2.8045960.

71. Bihan H, Espinosa C, Valdes-Socin H, Salenave S, Young J, Levasseur S, Assayag P, Beckers A, Chanson P. Long-term outcome of patients with acromegaly and congestive heart failure. J Clin Endocrinol Metab 2004;89:5308-5313. doi:10.1210/jc.2004-0821.

72. Saccà L, Napoli R, Cittadini A. Growth hormone, acromegaly, and heart failure: an intricate triangulation. Clin Endocrinol (Oxf) 2003;59:660-671. doi:10.1046/j.1365-2265.2003.01780.x.

73. Freestone NS, Ribaric S, Mason WT. The effect of insulin-like growth factor-1 on adult rat cardiac contractility. Mol Cell Biochem 1996;163-164:223-229.

74. Frustaci A, Chimenti C, Setoguchi M, Guerra S, Corsello S, Crea F, Leri A, Kajstura J, Anversa P, Maseri A. Cell death in acromegalic cardiomyopathy. Circulation 1999;99:1426-1434.

75. Narula J, Haider N, Virmani R, DiSalvo TG, Kolodgie FD, Hajjar RJ, Schmidt U, Semigran MJ, Dec GW, Khaw BA. Apoptosis in myocytes in end-stage heart failure. N Engl J Med 1996;335:11821189. doi:10.1056/NEJM199610173351603.
76. Sabbah HN, Sharov VG. Apoptosis in heart failure. Prog Cardiovasc Dis 1998;40:549-562.

77. Maison P, Tropeano A-I, Macquin-Mavier I, Giustina A, Chanson P. Impact of somatostatin analogs on the heart in acromegaly: a metaanalysis. J Clin Endocrinol Metab 2007;92:1743-1747. doi:10.1210/jc.2006-2547.

78. Chanson P, Timsit J, Masquet C, Guillausseau PJ, Warnet A, Lubetzki J. Heart failure responding to octreotide in patient with acromegaly. Lancet 1989;1:1263-1264.

79. Kuhn E, Maione L, Bouchachi A, Rozière M, Salenave S, Brailly-Tabard S, Young J, Kamenicky P, Assayag P, Chanson P. Long-term effects of pegvisomant on comorbidities in patients with acromegaly: a retrospective single-center study. Eur J Endocrinol 2015;173:693-702. doi:10.1530/EJE-15-0500. 80. Colao A. Improvement of cardiac parameters in patients with acromegaly treated with medical therapies. Pituitary 2012;15:50-58. doi:10.1007/s11102-011-0318-z.

81. Colao A, Marzullo P, Cuocolo A, Spinelli L, Pivonello R, Bonaduce D, Salvatore M, Lombardi G. Reversal of acromegalic cardiomyopathy in young but not in middle-aged patients after 12 months of treatment with the depot long-acting somatostatin analogue octreotide. Clin Endocrinol (Oxf) 2003;58:169-176.

82. Chatterjee S, Bavishi C, Sardar P, Agarwal V, Krishnamoorthy P, Grodzicki T, Messerli FH. Meta-analysis of left ventricular hypertrophy and sustained arrhythmias. Am J Cardiol 2014;114:1049_ 1052. doi:10.1016/j.amjcard.2014.07.015.

83. de Jong S, van Veen TAB, van Rijen HVM, de Bakker JMT. Fibrosis and cardiac arrhythmias. J Cardiovasc Pharmacol 2011;57:630-638. doi:10.1097/FJC.0b013e318207a35f.

84. Seale WL, Gang ES, Peter CT. The use of signal-averaged electrocardiography in predicting patients at high risk for sudden death. Pacing Clin Electrophysiol 1990;13:796-807.

85. Kahaly G, Olshausen KV, Mohr-Kahaly S, Erbel R, Boor S, Beyer J, Meyer J. Arrhythmia profile in acromegaly. Eur Heart J 1992;13:51-56.

86. Rodrigues EA, Caruana MP, Lahiri A, Nabarro JD, Jacobs HS, Raftery EB. Subclinical cardiac dysfunction in acromegaly: evidence for a specific disease of heart muscle. Br Heart J 1989;62:185-194.

87. Kırış A, Erem C, Turan OE, Civan N, Kırış G, Nuhoğlu I, Ilter A, Ersöz HO, Kutlu M. Left ventricular synchronicity is impaired in patients with active acromegaly. Endocrine 2013;44:200-206. doi:10.1007/s12020-012-9859-9.

88. Casini AF, Neto LV, Fontes R, França RF, Xavier SS, Gadelha MR. Aortic root ectasia in patients with acromegaly: experience at a single center. Clin Endocrinol (Oxf) 2011;75:495-500. doi:10.1111/ j.1365-2265.2011.04067.x.

89. Pereira AM, van Thiel SW, Lindner JR, Roelfsema F, van der Wall EE, Morreau H, Smit JW, Romijn JA, Bax JJ. Increased prevalence of regurgitant valvular heart disease in acromegaly. J Clin Endocrinol Metab 2004;89:71-5. doi:10.1210/jc.2003-030849. 90. Colao A, Spinelli L, Marzullo P, Pivonello R, Petretta M, Di Somma C, Vitale G, Bonaduce D, Lombardi G. High prevalence of cardiac valve disease in acromegaly: an observational, analytical, case-control study. J Clin Endocrinol Metab 2003;88:3196-201. doi:10.1210/jc.2002-021099.

91. van der Klaauw AA, Bax JJ, Roelfsema F, Bleeker GB, Holman ER, Corssmit EP, van der Wall EE, Smit JW, Romijn JA, Pereira AM. Uncontrolled acromegaly is associated with progressive mitral valvular regurgitation. Growth Horm IGF Res 2006;16:101-107. doi:10.1016/j.ghir.2006.02.002.

92. Bolfi F, Neves AF, Boguszewski CL, Nunes-Nogueira VS. Mortality in acromegaly decreased in the last decade: a systematic review and meta-analysis. Eur J Endocrinol 2018;179:59-71. doi:10.1530/EJE-18-0255.

93. Ritvonen E, Löyttyniemi E, Jaatinen P, Ebeling T, Moilanen L, Nuutila P, Kauppinen-Mäkelin R, Schalin-Jäntti C. Mortality in acromegaly: a 20-year follow-up study. Endocr Relat Cancer 2016;23:469-480. doi:10.1530/ERC-16-0106. 